Article

\title{
In Vitro and In Silico Mechanistic Insights into miR-21-5p-Mediated Topoisomerase Drug Resistance in Human Colorectal Cancer Cells
}

\author{
Jung-Chien Chen ${ }^{1,2,3,+}$, Yao-Yu Hsieh ${ }^{1,4,5,+}$, Hsiang-Ling Lo ${ }^{1,6}$, Albert Li ${ }^{1,6,7} \mathbb{1}$, \\ Chia-Jung Chou 1,6,8 and Pei-Ming Yang 1,6,8,9,*(D) \\ 1 PhD Program for Cancer Molecular Biology and Drug Discovery, College of Medical Science and Technology, \\ Taipei Medical University and Academia Sinica, Taipei 111, Taiwan \\ 2 Department of Surgery, Min-Sheng General Hospital, Taoyuan 168, Taiwan \\ 3 Central Clinic and Hospital, Taipei 106, Taiwan \\ 4 Division of Hematology and Oncology, Shuang Ho Hospital, Taipei Medical University, \\ New Taipei City 235, Taiwan \\ 5 Division of Hematology and Oncology, Department of Internal Medicine, School of Medicine, \\ College of Medicine, Taipei Medical University, Taipei 111, Taiwan \\ 6 Graduate Institute of Cancer Biology and Drug Discovery, College of Medical Science and Technology, \\ Taipei Medical University, Taipei 111, Taiwan \\ 7 School of Medicine, Taipei Medical University, Taipei 111, Taiwan \\ 8 TMU Research Center of Cancer Translational Medicine, Taipei 111, Taiwan \\ 9 Cancer Center, Wan Fang Hospital, Taipei Medical University, Taipei 111, Taiwan \\ * Correspondence: yangpm@tmu.edu.tw; Tel.: +886-2-2697-2035 (ext. 143) \\ + These authors contribute equally to this work.
}

Received: 2 August 2019; Accepted: 7 September 2019; Published: 9 September 2019

check for updates

\begin{abstract}
Although chemotherapy for treating colorectal cancer has had some success, drug resistance and metastasis remain the major causes of death for colorectal cancer patients. MicroRNA-21-5p (hereafter denoted as miR-21) is one of the most abundant miRNAs in human colorectal cancer. A Kaplan-Meier survival analysis found a negative prognostic correlation of miR-21 and metastasis-free survival in colorectal cancer patients (The Cancer Genome Atlas Colon Adenocarcinoma/TCGA-COAD cohort). To explore the role of miR-21 overexpression in drug resistance, a stable miR-21-overexpressing clone in a human DLD-1 colorectal cancer cell line was established. The 3-(4,5-dimethylthiazol-2-yl)-2,5-diphenyl tetrazolium bromide (MTT) cell viability assay found that miR-21 overexpression induced drug resistance to topoisomerase inhibitors (SN-38, doxorubicin, and etoposide/VP-16). Mechanistically, we showed that miR-21 overexpression reduced VP-16-induced apoptosis and concomitantly enhanced pro-survival autophagic flux without the alteration of topoisomerase expression and activity. Bioinformatics analyses suggested that miR-21 overexpression induced genetic reprogramming that mimicked the gene signature of topoisomerase inhibitors and downregulated genes related to the proteasome pathway. Taken together, our results provide a novel insight into the role of miR-21 in the development of drug resistance in colorectal cancer.
\end{abstract}

Keywords: autophagy; colorectal cancer; Connectivity Map; drug resistance; microRNA

\section{Introduction}

According to the global cancer statistics in 2018, colorectal cancer (CRC) is still the second essential contributor of cancer-related deaths in males and females worldwide [1]. Chemotherapeutics based on 5-fluorouracil (5-FU), in combination with oxaliplatin or irinotecan, are the standard regimen for CRC, 
which has increased the overall survival of CRC patients [2]. In addition, several molecular-targeted therapies have been developed, such as cetuximab and bevacizumab, which are monoclonal antibodies specific to epidermal growth factor receptor (EGFR) and vascular endothelial growth factor (VEGFR), respectively [2]. However, the acquisition of anticancer drug resistance remains the major challenge in treating CRC. A better characterization of the molecular mechanisms that are involved will provide clinical benefits for controlling and preventing the development of drug resistance.

MicroRNAs (miRNAs), approximately 19 to 25 nucleotide-long small noncoding RNAs, could suppress mRNA translation or stability through interacting with the 3'-untranslated region (3'-UTR) of target mRNAs. The alteration of miRNA expressions is frequently observed in human cancers, and these altered miRNAs have been shown to display either oncogenic or tumor-suppressive functions [3]. An oncogenic miRNA, miR-21, is overexpressed in CRC [4,5]. Tumor suppressor genes, such as programmed cell death 4 (PDCD4), phosphatase and tensin homolog (PTEN), and sprouty 2 (SPRY2), have been known as mRNA targets of miR-21. Silencing these genes stimulates cell proliferation, inhibits apoptosis, and enhances invasion and metastasis [6,7]. However, the role of miR-21 in drug resistance in $\mathrm{CRC}$, and the participated molecular mechanisms remains unclear.

Here, we established an miR-21-overexpressing DLD-1 human CRC cell line to investigate its role in drug resistance in CRC. We demonstrated that miR-21 overexpression induced drug resistance to topoisomerase inhibitors through reducing apoptotic induction and enhancing autophagic flux. Bioinformatics analyses further provided in silico mechanistic insights into miR-21-mediated drug resistance. Our results suggest a novel role of miR-21 in drug resistance in CRC.

\section{Materials and Methods}

\subsection{Chemicals and Reagents}

Lipofectamine RNAiMAX Transfection Reagent, Roswell Park Memorial Institute-1640 (RPMI-1640) medium, sodium pyruvate, L-glutamine, and antibiotic/antimycotic solution were from Life Technologies (Gaithersburg, MD, USA). Fetal bovine serum (FBS) was from GIBCO (Grand Island, NY, USA). Programmed cell death 4 (PDCD4; GTX104901), DNA topoisomerase I (TOP1; GTX63013), DNA topoisomerase II alpha (TOP2A; GTX100689), DNA topoisomerase II beta (TOP2B; GTX102640), Sequestosome 1 (SQSTM1/p62; GTX100685), Microtubule associated protein 1 light chain 3 beta (MAP1LC3B; GTX127375), Beclin 1 (GTX113039), Autophagy related 12 (ATG12; GTX124181), Lysosomal associated membrane protein 2 (LAMP2; GTX103214), and Glyceraldehyde-3-phosphate dehydrogenase (GAPDH; GTX100118) antibodies were from GeneTex (Hsinchu, Taiwan). The caspase-3 (3004-100) antibody was from Imgenex (San Diego, CA, USA). The autophagy related 7 (ATG7; sc-8668) antibody was from Santa Cruz Biotechnology (Santa Cruz, CA, USA). The ubiquitin (MAB1510) antibody was from EMD Millipore (Billerica, MA, USA). The poly(ADP-ribose) polymerase 1 (PARP1; 9542S) antibody was from Cell Signaling Technology (Beverly, MA, USA). Horseradish peroxidase (HRP)-labeled secondary antibodies were from Jackson ImmunoResearch (West Grove, PA, USA). pCMV-MIR and pCMV-MIR21 plasmids were from OriGene (Rockville, MD, USA). ON-TARGETplus human ATG7 and Non-Targeting SMARTpool siRNAs were from Dharmacon (Lafayette, CO, USA). The PolyJet DNA Transfection Reagent was from SignaGen Laboratories (Ijamsville, MD, USA). Geneticin (G418) was from Invivogen (San Diego, CA, USA). The GENEzol TriRNA Pure Kit was from Geneaid Biotech (New Taipei City, Taiwan). The miScript II RT Kit, miScript SYBR Green PCR Kit, and Hs_miR-21_2 (hsa-miR-21-5p) miScript Primer Assay were from Qiagen (Valencia, CA, USA). The iScript cDNA Synthesis Kit was from Bio-Rad Laboratories (Richmond, CA, USA). Dimethyl sulfoxide (DMSO), MG132, and 3-(4,5-dimethylthiazol-2-yl)-2,5-diphenyl tetrazolium bromide (MTT) were from Sigma Chemical (St. Louis, MO, USA). Bafilomycin A1 and doxorubicin were from LC Laboratories (Woburn, MA, USA). 5-Fluorouracil (5-FU) was from Merck Millipore (Billerica, MA, USA). Etoposide (VP-16) and 7-ethyl-10-hydroxy-camptothecin (SN-38) were from Adooq BioScience (Irvine, CA, USA). Rapamycin was from Cayman Chemical (Ann Arbor, MI, USA). An enhanced 
chemiluminescence (ECL) system was from Perkin-Elmer (Boston, MA, USA). Phosphatase and protease inhibitor cocktails were from Roche (Indianapolis, IN, USA). Hybond-C Extra nitrocellulose membranes were from GE Healthcare (Piscataway, NJ, USA). X-ray film and 2x SYBR Green PCR Master Mix were from Roche (Indianapolis, IN, USA).

\subsection{Cell Culture and Transfection}

DLD-1 human colorectal cancer cells were cultivated in RPMI-1640 medium containing 10\% FBS, $1 \%$ L-glutamine, $1 \mathrm{mM}$ sodium pyruvate, and $1 \%$ antibiotic/antimycotic solution. Cells were incubated in a humidified $37^{\circ} \mathrm{C}, 5 \% \mathrm{CO}_{2}$ incubator. To establish stable miR-21-overexpressing DLD-1 (DLD-1-miR-21) and corresponding vector-overexpressing (DLD-1-vector) cell lines, parental DLD-1 cells were transfected with a plasmid encoding human miR-21 or its control vector (pCMV-MIR) using the PolyJet transfection reagent. Stable clones were selected with $1 \mathrm{mg} / \mathrm{mL}$ G418 for 2 months. Single clones were selected based on the expression of the green fluorescent protein (GFP) reporter and then pooled together for subsequent experiments. For transient ATG7 knockdown analysis, human ATG7 and control scramble siRNAs were transfected into cells by Lipofectamine RNAiMAX Transfection Reagent. After 24 to $48 \mathrm{~h}$, the transfected cells were used for further experiments.

\subsection{Determination of Cell Proliferation and Cell Viability}

To determine cell proliferation, the cells $\left(10^{5}\right)$ were spread in $60-\mathrm{mm}$ dishes and cultured for approximately 1 to 4 days (three dishes per time point). Then, cells were harvested by trypsinization, and the cell number was counted with a hemocytometer (Marienfeld, Lauda-Königshofen, Germany). For MTT cell viability, cells were spread in 96-well plates and exposed to drugs for $72 \mathrm{~h}$ (five wells per treatment). At the end of drug incubation, MTT $(0.5 \mathrm{mg} / \mathrm{mL})$ was directly added to cells and cultured for an additional $4 \mathrm{~h}$. Then, the medium was removed, and DMSO was added to dissolve the blue MTT formazan precipitates. Cell viability was determined based on the absorbance at $570 \mathrm{~nm}$.

\subsection{Quantitative Real-time Polymerase Chain Reaction ( $q P C R$ )}

Total RNA was isolated with a GENEzol TriRNA Pure Kit. To determine the miR-21 expression, first-strand complementary (c) DNA was synthesized using a miScript II RT Kit, and then qPCR was performed using a miScript SYBR Green PCR Kit and Hs_miR-21_2 miScript Primer assays. To determine mRNA expression, first-strand cDNA was synthesized using an iScript cDNA Synthesis Kit, and then the qPCR was performed using 2x SYBR Green PCR Master Mix. The primers specific to human PDCD4 and $\beta$-actin were as follows: $5^{\prime}$-TGGATTAACTGTGCCAACCA- ${ }^{\prime}$ and $5^{\prime}$-TCTCAAATGCCCTTTCATCC-3' (PDCD4); $5^{\prime}$-GTTGCTATCCAGGCTGTGCT- ${ }^{\prime}$ and $5^{\prime}$-AGGGCAT ACCCCTCGTAGAT-3' ( $\beta$-actin). Each assay was performed in triplicate on a LightCycler Nano Real-Time PCR System (Roche). The related gene expression was calculated by the comparative CT method.

\subsection{Western Blot Analysis}

Cells were lysed on ice for $30 \mathrm{~min}$ in ice-cold lysis buffer (50 mM Tris- $\mathrm{HCl}$ (pH 7.5), $2 \mathrm{mM}$ EDTA, $150 \mathrm{mM} \mathrm{NaCl}, 1 \mathrm{mM} \mathrm{MgCl}$, 1\% NP-40, $1 \mathrm{mM} \mathrm{DTT,} \mathrm{10 \%} \mathrm{glycerol,} \mathrm{1×} \mathrm{protease,} \mathrm{and} \mathrm{phosphatase}$ inhibitor cocktails). Protein lysates were separated on an SDS-polyacrylamide gel (SDS-PAGE) and then transferred onto a nitrocellulose membrane. After pre-hybridization in 5\% skim milk/TBST $(20 \mathrm{mM}$ Tris- $\mathrm{HCl}$ (pH 7.5), $150 \mathrm{mM} \mathrm{NaCl}$, and $0.05 \%$ Tween-20) for $1 \mathrm{~h}$, the membrane was hybridized with a primary antibody overnight at $4{ }^{\circ} \mathrm{C}$ in $1 \%$ bovine serum albumin (BSA)/TBST. After washing with TBST buffer, the membrane was hybridized with an HRP-conjugated secondary antibody for $1 \mathrm{~h}$ in $1 \%$ BSA/TBST. Then, the membrane was washed with TBST and rinsed with TBS. The chemiluminescence was developed with an ECL system and exposed to X-ray film. 


\subsection{Band-depletion Assay}

Cells in 60-mm dishes were treated with VP-16 for $1 \mathrm{~h}$, and immediately lysed with $150 \mu \mathrm{L}$ of $1 \times$ SDS sample buffer. After vortexing and boiling at $100{ }^{\circ} \mathrm{C}$ for $5 \mathrm{~min}$, protein was separated by $7.5 \%$ SDS-PAGE, and then Western blot analysis was performed.

2.7. Microarray, Connectivity Map (CMap), and Kyoto Encyclopedia of Genes and Genomes (KEGG) Pathway Enrichment Analyses

Total RNA was purified with the GENEzol TriRNA Pure Kit. mRNA profiles were examined using the Human OneArray Plus (Phalanx Biotech, Hsinchu, Taiwan). The raw data were deposited in the National Center for Biotechnology Information Gene Expression Omnibus (NCBI GEO) database (GSE136665). Differentially expressed genes (DEGs) were prepared according to the criteria: $\log 2$ ratio $\geq 1$ or $\leq-1 ; p$ value $<0.05$. The full DEG list was shown in File S1. For the next-generation CMap analysis, the 193 most upregulated and 167 downregulated genes (Table S1) were input to the CLUE (https://clue.io/) [8] database to obtain 150 upregulated and 150 downregulated valid genes for querying (SEP 06, 2019, date last accessed). For the KEGG pathway enrichment analysis, the best (smallest $p$ value) 3000 DEGs were prepared to run a Gene Set Enrichment Analysis (GSEA) against the canonical pathway database.

\subsection{CellMinerCDB Analysis}

The CellMinerCDB (https://discover.nci.nih.gov/cellminercdb/) is an interactive web-based portal for querying the relationship between genomic and pharmacological data from large-scale cancer cell lines [9]. For the correlation between TOP2B mRNA expression and VP-16 drug activity, both the "X- and Y-Axis Cell Line Sets" were set to "CTRP". Cancer Therapeutics Response Portal (CTRP; https://portals.broadinstitute.org/ctrp.v2.1/) is a database linking genetic, lineage, and other cellular features of cancer cell lines to small-molecule sensitivity [10-12]. The "X-Axis Data Type" and "Y-Axis Data Type" were set to "exp: mRNA Expression (log2)" and "act: Drug Activity (AUC)", respectively. The identifiers for X-and Y-axis were set to "TOP2B" and "etoposide", respectively. For the correlation between miR-21 expression and VP-16 drug activity, the cell line set and data type of the X-axis were set to "CCLE" and "mir: MicroRNA", respectively. The identifier for miR-21 was set to "hsa-miR-21".

\subsection{Kaplan-Meier Survival Analysis}

The prognostic impact of miR-21 in CRC was analyzed using the PROGmiR database (http: //www.compbio.iupui.edu/progmir) [13]. The input "has-mir-21" was queried, and Kaplan-Meier survival plots were generated based on the expression data of colon adenocarcinoma (COAD) from The Cancer Genome Atlas (TCGA; https://tcga-data.nci.nih.gov/tcga). Patients with high ( $n=181)$ and low $(n=180)$ miR-21 expression were bifurcated at the median value. The prognostic impact of the miR-21-downregulated proteasome gene signature (PSME3, PSMA1, PSMA2, PSMA3, PSMB2, PSMB3, PSMB4, PSMB5, PSMB8, PSMB10, PSMC2, PSMC3, PSMC4, PSMC5, PSMC6, PSMD3, PSMD4, PSMD11, PSME1, PSMF1, and PSMD6) in CRC was evaluated using the PROGgeneV2 database (http://www.compbio.iupui.edu/proggene/) [14]. Two CRC patient datasets (GSE28722 and GSE28814) [15] were employed to generate the Kaplan-Meier survival plots. Patients with high $(n=61$ or 63$)$ and low ( $n=61$ or 62$)$ miR-21 expression in GSE28722 and GSE28144, respectively, were bifurcated at the median value.

\section{Results}

\section{1. miR-21 Overexpression is Correlated with Drug Resistance to Topoisomerase Inhibitors}

To understand the prognostic implications of miR-21 in the CRC, the PROGmiR tool (http: //www.compbio.iupui.edu/progmir) [13] was employed to query the term "has-mir-21" based on the expression data of colon adenocarcinoma (COAD) from The Cancer Genome Atlas (TCGA; 
https://tcga-data.nci.nih.gov/tcga). Kaplan-Meier survival plots for overall and metastatic-free survival in patients with high and low miR-21 expression were generated. The overall survival did not significantly differ between miR-21-high-expressing and miR-21-low-expressing patients (Figure 1A). However, patients with higher miR-21 expression had poor metastasis-free survival $(p<0.05)$, suggesting the involvement of miR-21 in CRC metastasis (Figure 1B). To investigate how miR-21 contributes to the metastasis of the CRC, a stable miR-21-overexpressing DLD-1 human CRC cell line (DLD-1-miR-21) and a corresponding vector-overexpressing cell line (DLD-1-vector) were established. The overexpression of miR-21 was authenticated by a quantitative real-time polymerase chain reaction (qPCR) (Figure 2A). The expression of PDCD4 messenger (m)RNA and protein, a well-known miR-21 target [16], was downregulated in DLD-1-miR-21 cells (Figure 2A,B). Similar growth rates were observed in DLD-1-vector and DLD-1-miR-21 cells (Figure 2C). However, bright-field microscopy observation found that DLD-1-miR-21 cells tend to gather together in monolayer culture (Figure 2D).

FOLFIRI is a standard chemotherapy for CRC, which consists of the following drugs: leucovorin (a vitamin B derivative), 5-FU (a thymidylate synthase inhibitor), and irinotecan (a topoisomerase I inhibitor). The development of anticancer drug resistance is a biological characteristic of metastatic CRC [17]. To investigate whether miR-21 overexpression contributes to the drug resistance of CRC, DLD-1-vector and DLD-1-miR-21 cells were challenged with 5-FU, SN-38 (the active metabolite of irinotecan), and topoisomerase II inhibitors, including doxorubicin and etoposide (VP-16); then, an MTT cell viability assay was performed. The results (Figure 2E) showed that both DLD-1-vector and DLD-1-miR-21 cells exhibited similar sensitivities to 5-FU treatment. However, DLD-1-miR-21 cells were significantly more susceptible to treatment with SN-38, doxorubicin, and VP-16. Therefore, DLD-1-miR-21 cells were specifically resistant to topoisomerase inhibitors.

To confirm the role of miR-21 in topoisomerase drug resistance, the drug sensitivity of Cancer Cell Line Encyclopedia (CCLE) [18,19] cell lines to VP-16 and doxorubicin were analyzed using the CellMinerCDB (https://discover.nci.nih.gov/cellminercdb/), which is a web-based resource for integrating pharmacological and genomic analyses of cancer cell lines [9]. As shown in Figure S1, the drug activity of VP-16 and doxorubicin was proportional to the gene expression of their target TOP2B, but inversely proportional to miR-21 gene expression. Therefore, cancer cells with higher $\mathrm{miR}-21$ respond poorer to topoisomerase inhibitors.

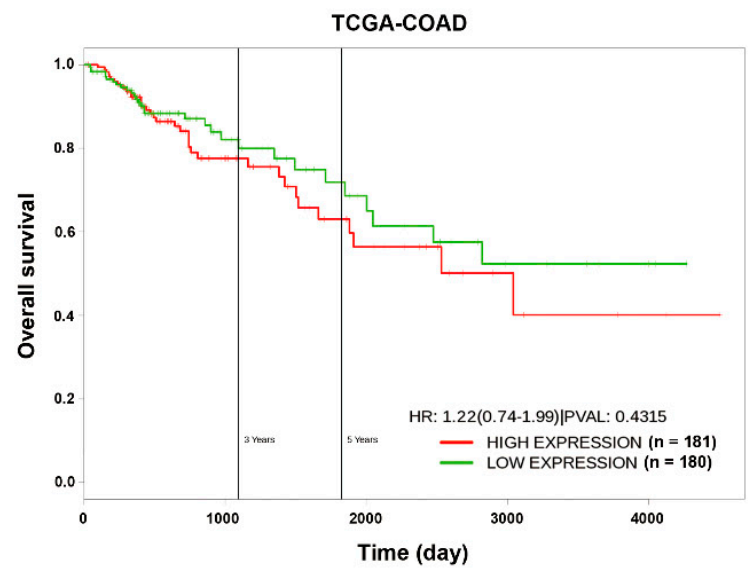

(A)

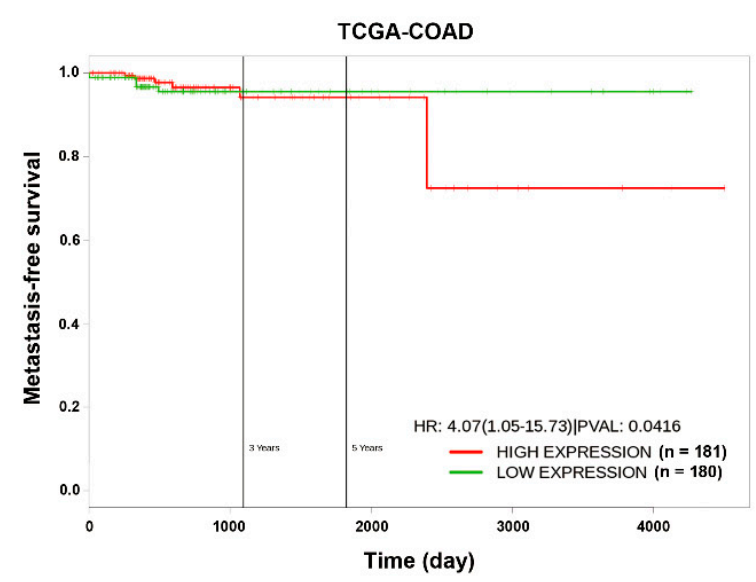

(B)

Figure 1. The prognostic impact of microRNA-21-5p (miR-21) on overall (A) and metastasis-free (B) survival in colorectal cancer (CRC). The prognostic impact of miR-21 in CRC was analyzed using the PROGmiR database (http://www.compbio.iupui.edu/progmir). The input "has-mir-21" was queried, and Kaplan-Meier survival plots were generated based on the expression data of colon adenocarcinoma (COAD) from The Cancer Genome Atlas (TCGA; https://tcga-data.nci.nih.gov/tcga). Patients with high $(n=181)$ and low $(n=180)$ miR-21 expression were bifurcated at the median value. HR, hazard ratio; PVAL, $p$ value. 
A

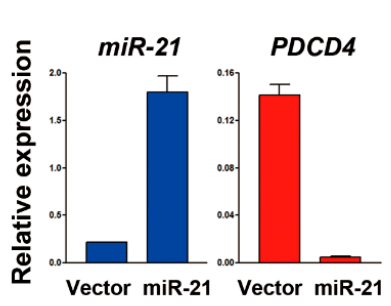

B

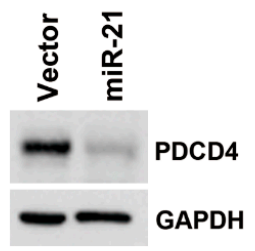

C

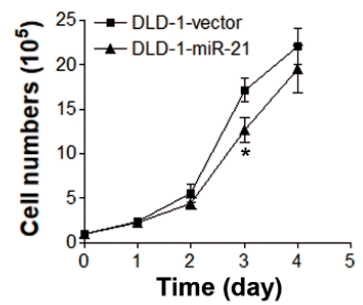

D

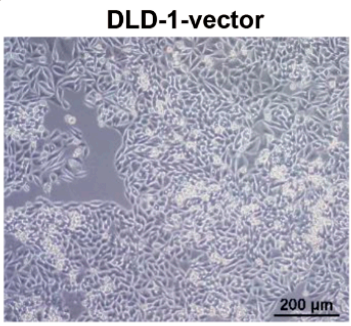

E
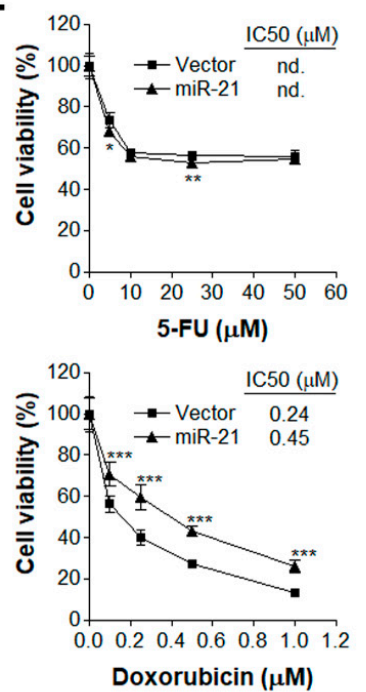

DLD-1-miR-21
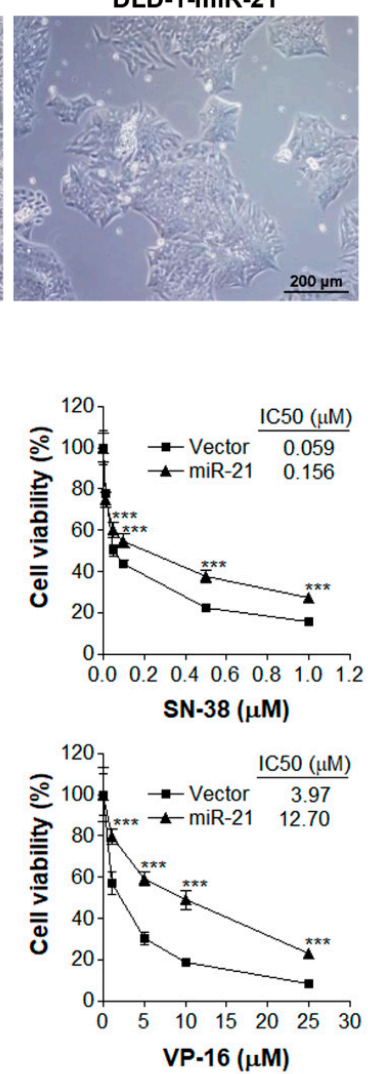

F

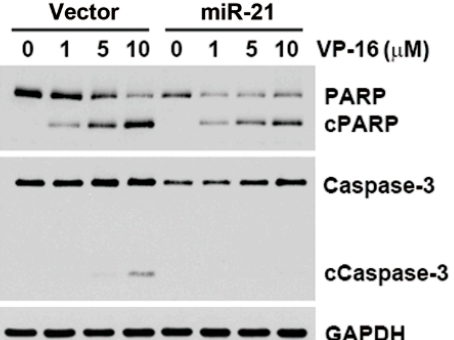

G

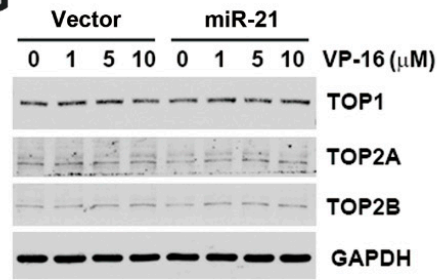

H

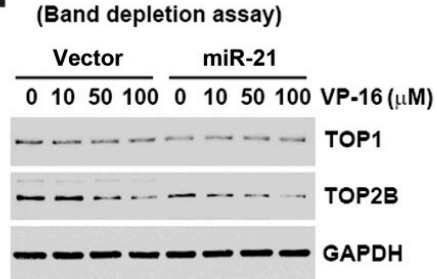

Figure 2. Effect of miR-21 overexpression on chemosensitivity. (A) mRNA expression of miR-21 and programmed cell death 4 (PDCD4) in corresponding vector-overexpressing DLD-1 (DLD-1-vector) and miR-21-overexpressing DLD-1 (DLD-1-miR-21) cells were analyzed by qPCR. (B) Protein expressions of PDCD4 in DLD-1-vector and DLD-1-miR-21 cells were analyzed by Western blot analysis. (C) Growth rates of DLD-1-vector and DLD-1-miR-21 cells were measured by cell counts at approximately 1 to 4 days. $p<0.05\left(^{*}\right)$ indicates significant differences between DLD-1-miR-21 and DLD-1-vector cells. (D) Cell morphology was observed under bright-field microscopy. (E) DLD-1-vector and DLD-1-miR-21 cells were treated with various doses of 5-fluorouracil (5-FU), SN-38, doxorubicin, and VP-16 for $72 \mathrm{~h}$. Cell viability was analyzed by an 3-(4,5-dimethylthiazol-2-yl)-2,5-diphenyl tetrazolium bromide (MTT) assay. $p<0.05\left(^{*}\right), p<0.01\left(^{* *}\right)$, or $\left.p<0.001{ }^{* * *}\right)$ indicates significant differences between DLD-1-miR-21 and DLD-1-vector cells. n.d., not determined. (F) DLD-1-vector and DLD-1-miR-21 cells were treated with various doses of VP-16 for $48 \mathrm{~h}$. Whole-cell lysates were prepared and subjected to a Western blot analysis. (G) DLD-1-vector and DLD-1-miR-21 cells were treated with various doses of VP-16 for $24 \mathrm{~h}$. Whole-cell lysates were prepared and subjected to a Western blot analysis. (H) DLD-1-vector and DLD-1-miR-21 cells were treated with various doses of VP-16 for $1 \mathrm{~h}$. A band-depletion assay was performed as described in "Materials and Methods". 
3.2. miR-21 Overexpression Attenuates VP-16-Induced Apoptosis without Affecting Expressions or Activities of Topoisomerases

To investigate the mechanism of drug resistance to topoisomerase inhibitors by miR-21, whether drug treatment inhibited miR-21 expression was first examined. Since VP-16 exhibited the most differential effect on the cell viability of DLD-1-vector and DLD-1-miR21 cells (Figure 2E), we selected VP-16 as a representative for further investigation. As shown in Figure S2, VP-16 reduced the miR-21 expression level to 35\% and 37\% in DLD-1-vector and DLD-1-miR-21 cells, respectively. Thus, the inhibition of miR-21 may not be responsible for the differential effects of VP-16 in these two cell lines. Cell apoptosis was further examined by cleaving poly(ADP-ribose) polymerase 1 (PARP1) and caspase-3. PARP1 is a $116-\mathrm{kDa}$ enzyme that is cleaved into $89-\mathrm{kDa}$ and $24-\mathrm{kDa}$ fragments during apoptosis [20]. As shown in Figure 2F, higher levels of cleaved PARP1 and caspase-3 were observed in VP-16-treated DLD-1-vector cells compared to DLD-1-miR-21 cells. Therefore, miR-21 overexpression induced drug resistance to VP-16 through reducing drug-induced apoptosis.

Since both the elevated and reduced expression of topoisomerases are reported to be associated with resistance to topoisomerase inhibitors [21,22], it is possible that miR-21 overexpression results in the downregulation of topoisomerases, leading to drug resistance. To test this possibility, expressions of topoisomerase I (TOP1) and II (TOP2A and TOP2B) were examined by Western blot analysis. However, the expression of TOP1, TOP2A, and TOP2B proteins were similar between DLD-1-vector and DLD-1-miR-21 cells (Figure 2G). Furthermore, a band-depletion assay was used to measure topoisomerase activity by detecting catalytic topoisomerase-DNA cleavage complexes trapped by topoisomerase inhibitors. During sodium dodecylsulfate (SDS)-polyacrylamide gel electrophoresis (PAGE), topoisomerase-DNA complexes have lower mobility than free enzymes [23]. As shown in Figure 2H, VP-16 depleted TOP2B in both DLD-1-vector and DLD-1-miR-21 cells, suggesting that miR-21 overexpression did not alter topoisomerase activity. Therefore, miR-21 overexpression leads to drug resistance and VP-16 without affecting the expressions or activities of topoisomerases.

\subsection{Accelerated Autophagic flux is Associated with miR-21-Induced Drug Resistance}

Autophagy (autophagic cell death) has been categorized as type II programmed cell death [24]. However, autophagy can also act as a stress-adaptation process that avoids cell death [25]. To investigate whether VP-16 also induces autophagy, the expression of two autophagy markers (LC3-II and p62) [26] was examined. LC3-I is modified by adding a phosphatidylethanolamine (PE) and converted into LC3-II, and p62 is degraded during the autophagic process [26]. As shown in Figure 3A, VP-16 did not significantly induce autophagy in either DLD-1-vector or DLD-1-miR-21 cells. Interestingly, treatment with VP-16 for $48 \mathrm{~h}$ blocked the conversion of LC3-I to LC3-II in DLD-1-vector cells, although the corresponding level of p62 was reduced. However, the basal level of LC3-II was higher in DLD-1-miR-21 cells, suggesting that miR-21 overexpression accelerated autophagic flux. Indeed, VP-16 induced more LC3-II accumulation at $24 \mathrm{~h}$ and enhanced p62 and LC3-II degradation at $48 \mathrm{~h}$. Therefore, autophagy exhibits a protective role in response to VP-16 treatment, which was amplified by miR-21 overexpression.

To investigate the role of autophagy in the anticancer effect of VP-16, an autophagy inducer, rapamycin-which is a mammalian target of rapamycin (mTOR) inhibitor-was used to enhance autophagic flux. As shown in Figure 3B, rapamycin inhibited the VP-16-induced cleavage of PARP1 and caspase- 3 in both cell types, suggesting that autophagy plays a cytoprotective role. To confirm this phenomenon, cell viability was evaluated by an MTT assay. Consistently, rapamycin protected both DLD-1-vector and DLD-1-miR-21 cells from VP-16's cytotoxicity (Figure 3C). In contrast, the blockade of autophagosome-lysosome fusion by bafilomycin A1 (a vacuolar-type $\mathrm{H}^{+}$-ATPase inhibitor) induced more cell-killing in DLD-1-miR-21 cells (Figure 3D). To further ascertain the role of autophagy, ATG7 expression was knocked down by siRNA to inhibit autophagy, and the enhancement of VP-16-induced apoptosis in both DLD-1-vector and DLD-1-miR-21 cells was found (Figure 3E). Therefore, miR-21 
overexpression contributes to drug resistance through accelerating autophagic flux, which did not result from the different expression levels of autophagy-related proteins between two cells (Figure 3F).

A
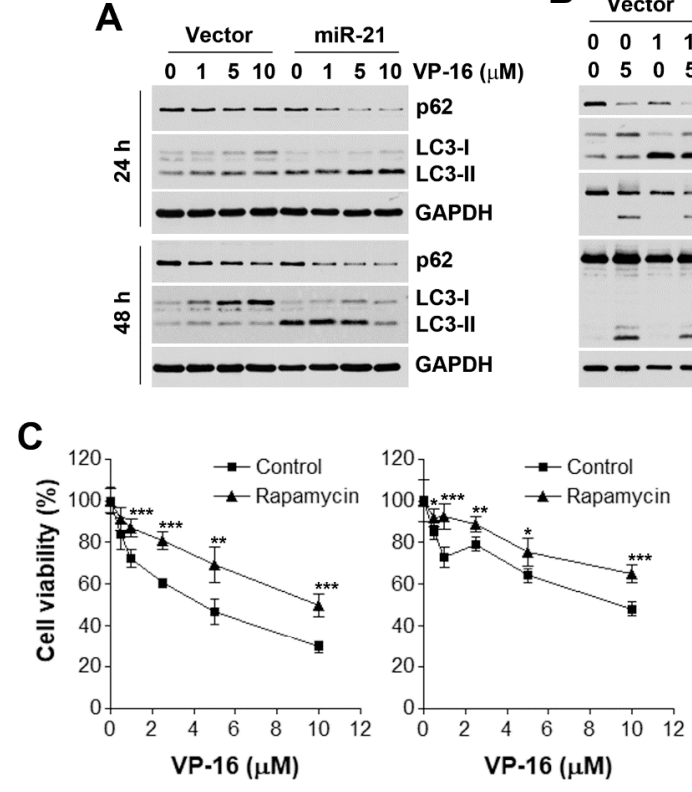

E

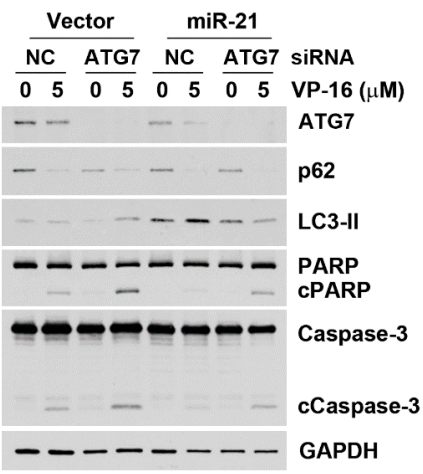

\section{B}

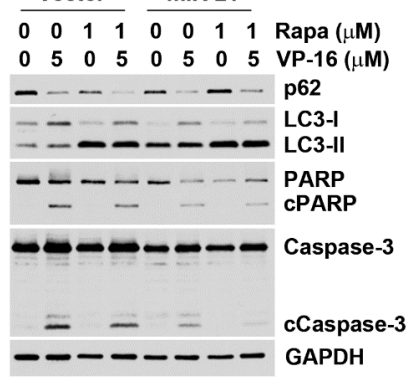

D ${ }_{120} \square$ DLD-1-vector

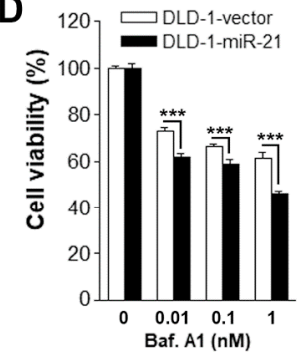

$\mathbf{F}$

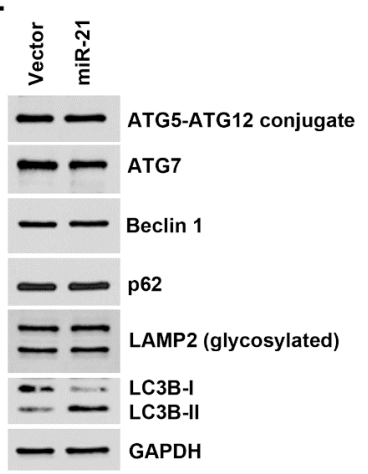

Figure 3. Effect of autophagy on miR-21-induced drug resistance. (A) DLD-1-vector and DLD-1-miR-21 cells were treated with various doses of VP-16 for 24 and $48 \mathrm{~h}$. Whole-cell lysates were prepared and subjected to a Western blot analysis. (B) DLD-1-vector and DLD-1-miR-21 cells were treated with various doses of VP-16 with or without $1 \mu \mathrm{M}$ rapamycin (Rapa) for $48 \mathrm{~h}$. Whole-cell lysates were prepared and subjected to a Western blot analysis. (C) DLD-1-vector and DLD-1-miR-21 cells were treated with various doses of VP-16 with or without $0.5 \mu \mathrm{M}$ rapamycin for $72 \mathrm{~h}$. Cell viability was examined by an MTT assay. $p<0.05\left(^{*}\right), p<0.01\left(^{* *}\right)$, or $p<0.001\left(^{* * *}\right)$ indicates significant differences between rapamycin-treated and control cells. (D) DLD-1-vector and DLD-1-miR-21 cells were treated with various doses of bafilomycin A1 for $72 \mathrm{~h}$. Cell viability was analyzed by an MTT assay. $p<0.001$ $\left.{ }^{* * *}\right)$ indicates significant differences between DLD-1-vector and DLD-1-miR-21 cells. (E) DLD-1-vector and DLD-1-miR-21 cells were transfected with ATG7 or non-targeting siRNAs for $48 \mathrm{~h}$ before exposure to $5 \mu \mathrm{M}$ VP- 16 for $48 \mathrm{~h}$. Then, whole-cell lysates were prepared and subjected to a Western blot analysis. (F) The untreated whole-cell lysates from DLD-1-vector and DLD-1-miR-21 cells were analyzed by Western blot analysis.

\subsection{In Silico Analyses Reveal the Mechanistic Role of miR-21 Overexpression in the Development of Drug Resistance}

Since one miRNA may regulate multiple target genes and other genes indirectly through modulating the corresponding transcription factors, we employed bioinformatics approaches to 
gain in silico mechanistic insights into the role of miR-21 in drug resistance. The Connectivity Map (CMap) is a web-based database consisting of gene expression signatures from small molecule-treated human cancer cells. By mining and comparing the queried and existing gene signatures, one can find connections among genetic knockdown/overexpression or small molecules with similar action mechanisms $[8,27,28]$. A microarray analysis of DLD-1-miR-21 and DLD-1-vector cells was performed, and differentially expressed genes (DEGs; Table S1) were prepared to query the next-generation CMap database, CLUE (https://clue.io/) [8]. As shown in Figure 4A, drugs or the knockdown/overexpression of genes were classified as perturbational classes according to their functions. The top 10 most similar perturbational classes to miR-21 overexpression are shown. Interestingly, the gene expression profile of miR-21-overexpressing DLD-1 cells was similar to that of topoisomerase inhibitors, with a median score of 90.72. In particular, the average score of the HT-29 human CRC cell line treated with topoisomerase inhibitors was 97.26. Therefore, we propose that miR-21 overexpression mimics the gene signature of topoisomerase inhibitors and escapes from a drug-induced cytotoxicity, leading to drug resistance in the CRC.

A

\begin{tabular}{|c|c|c|c|c|c|c|c|c|c|c|c|}
\hline \multicolumn{9}{|c|}{ Cell ID } & \multirow{3}{*}{ 息 } & \multirow[b]{3}{*}{$\begin{array}{l}\text { Median } \\
\text { Score }\end{array}$} & \multirow{3}{*}{ 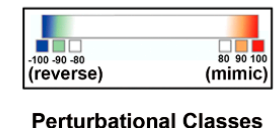 } \\
\hline \multirow[b]{2}{*}{ סु } & \multirow[b]{2}{*}{ 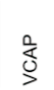 } & \multirow[b]{2}{*}{ 㗭 } & \multirow[b]{2}{*}{ 亭 } & & \multirow{2}{*}{ 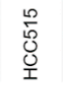 } & \multirow[b]{2}{*}{ 蛋 } & & \multirow{2}{*}{$\begin{array}{l}\text { N } \\
\text { 핖 }\end{array}$} & & & \\
\hline & & & & & & & & & & & \\
\hline 92.81 & 92.70 & 99.23 & 94.62 & 89.43 & \begin{tabular}{|l|l}
57.77 \\
\end{tabular} & 83.33 & 64 & 98.35 & & $\overline{93.72}$ & CDK inhibitor \\
\hline 92.71 & & 12.02 & & 96.47 & & 51.03 & 95.09 & 72.75 & 95.60 & 92.7 & eat st \\
\hline 89.35 & .37 & 83.00 & 62.01 & 88.60 & 94.19 & 97.26 & 92.08 & 89.22 & 51 & 90.72 & Topoisomeras \\
\hline 49.99 & 81.19 & 24.02 & 86.79 & 96.36 & 75.45 & 49.05 & 94.20 & 97.64 & & & AK ir \\
\hline 38.30 & 61.66 & & 78.98 & & & & \begin{tabular}{|l|l}
87.17 \\
\end{tabular} & 80.28 & & & otea \\
\hline 90.24 & & 85.99 & 95.16 & 0.00 & 37.46 & 77.61 & 76.25 & 72.04 & & 318 & $\mathrm{HF}$ act \\
\hline 80.26 & 61.83 & \begin{tabular}{|l|l|}
64.17 \\
\end{tabular} & 82.07 & \begin{tabular}{|l|l}
80.59 \\
\end{tabular} & 20.76 & 79.05 & 98.06 & 92.74 & 92.31 & 30.42 & ysine acetyltra \\
\hline 3.45 & -69.51 & 79.53 & 88.15 & \begin{tabular}{|l|l}
80.24 \\
\end{tabular} & 78.04 & \begin{tabular}{|l|l|}
16.40 \\
\end{tabular} & 62.61 & 83.49 & \begin{tabular}{|l|l|}
87.87 \\
\end{tabular} & 7 & ill 0 \\
\hline & 8 & 77.97 & 46.71 & 86.33 & & 91.83 & 37.56 & 80.7 & & & \\
\hline 3.81 & 82.92 & 84.18 & 51.71 & \begin{tabular}{|l|l}
89.77 \\
\end{tabular} & 47.04 & 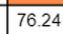 & 78.39 & | 41.61 & 81.29 & 78.60 & oteasome inhibitor \\
\hline
\end{tabular}

B

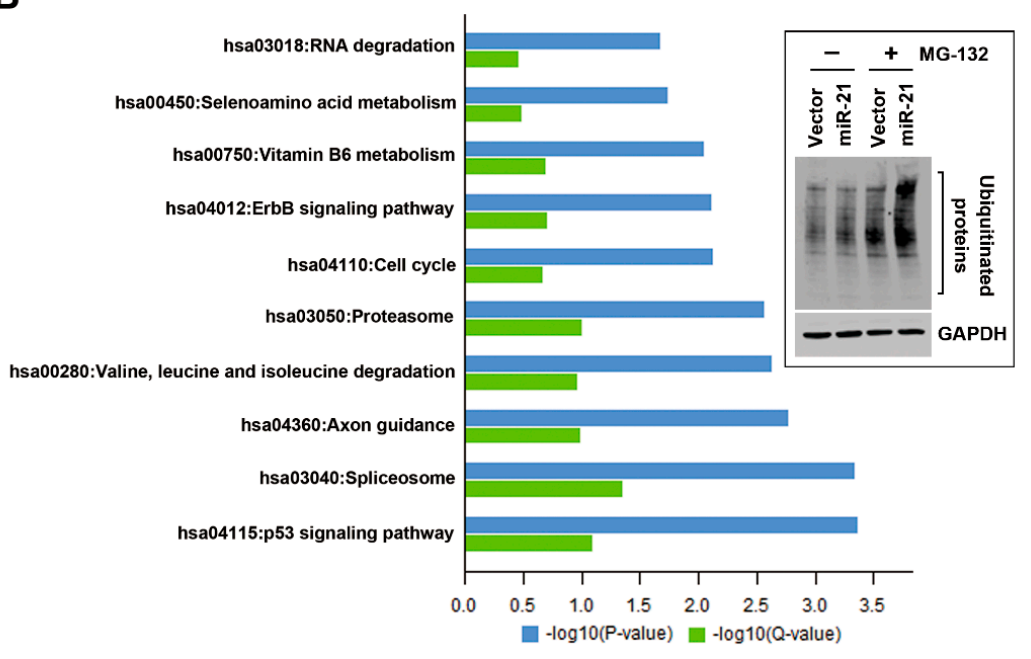

Figure 4. Microarray analysis of DLD-1-miR-21 cells. The total RNA isolated from DLD-1-vector and DLD-1-miR-21 cells was subjected to a microarray analysis as described in "Materials and Methods". Differentially expressed genes (DEGs) were prepared for the next-generation Connectivity Map (CMap) analysis (A) and Kyoto Encyclopedia of Genes and Genomes (KEGG) pathway enrichment analysis (B). In (A), the top 10 most similar perturbational classes to miR-21 overexpression are shown. The gray grids indicate "not measured". In (B), the top 10 enriched pathways are plotted on the Y-axis versus a measure of significance (negative logarithm of the $p$ value or Q-value) on the $\mathrm{X}$-axis. The $\mathrm{Q}$-value was calculated by Benjamini. Embedded figure in (B): DLD-1-vector and DLD-1-miR-21 cells were treated with or without $10 \mu \mathrm{M}$ MG132 for $4 \mathrm{~h}$. Whole-cell lysates were prepared and subjected to Western blot analysis. 
The CMap analysis also indicated that miR-21 overexpression mimicked "proteasome pathway loss-of-function (LOF)" and "proteasome inhibitor" (Figure 4A). The ubiquitin-proteasome and autophagy-lysosome pathways, two major intracellular protein-degradation systems, usually act in a coordinated and complementary manner [29]. For example, the inhibition of proteasome activity was shown to induce autophagy [30]. Therefore, we propose that accelerating autophagic flux might be due to the inhibition of the ubiquitin-proteasome protein degradation system by miR- 21 . In support of this notion, a Kyoto Encyclopedia of Genes and Genomes (KEGG) [31-33] pathway enrichment analysis found that the proteasome pathway was enriched in miR-21-overexpressing DLD-1 cells (Figure 4B). Genes encoding core and regulatory particles of the proteasome system were downregulated by miR-21 overexpression (Figure 5, Table S2). The inhibition of a proteasome pathway will lead to the accumulation of ubiquitin-conjugated proteins. Indeed, higher levels of ubiquitinated proteins were found in DLD-1-miR-21 cells with or without a proteasome inhibitor, MG132 (Figure 4B, the embedded figure).
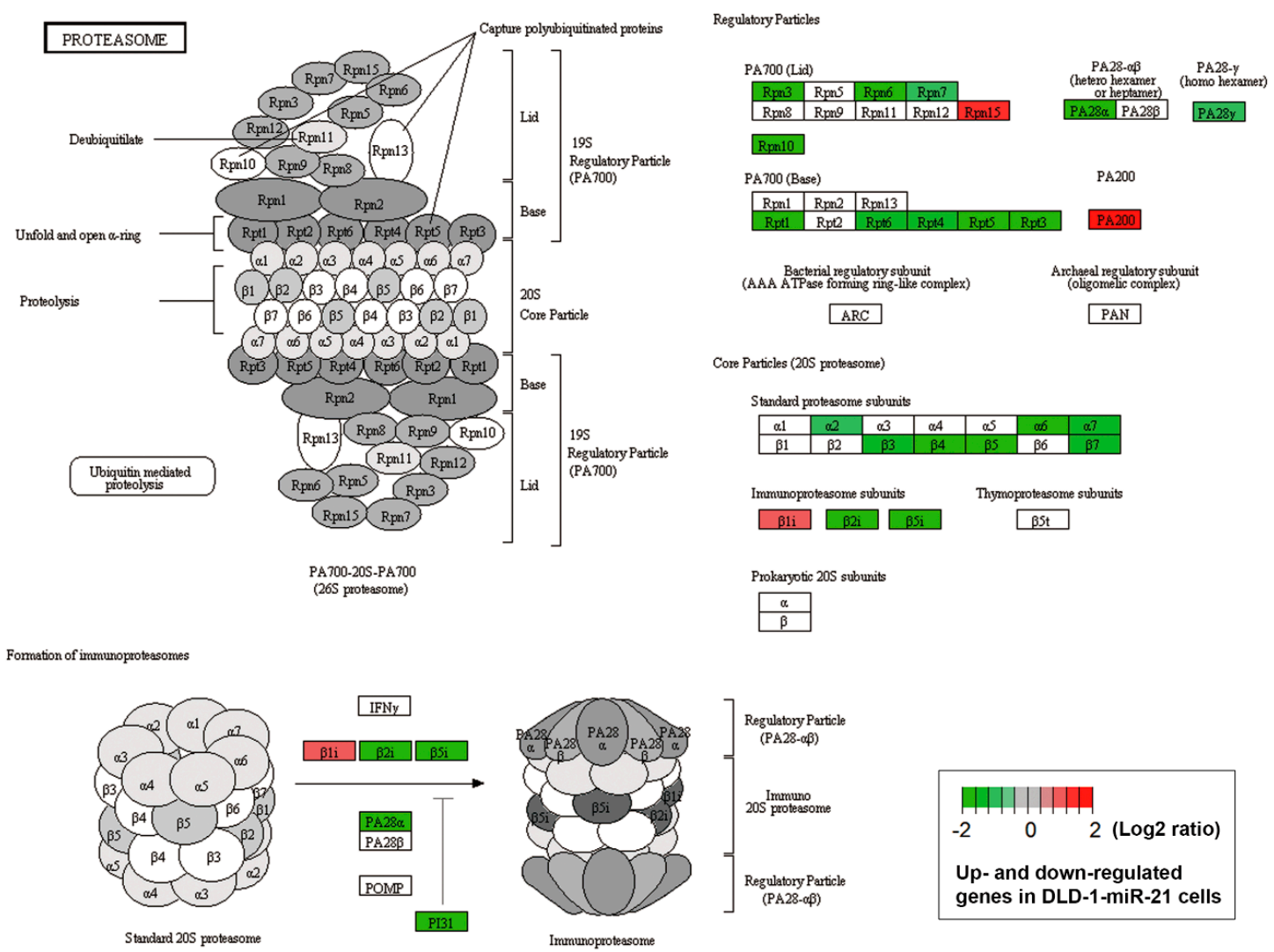

Figure 5. Proteasome pathway mapping of altered genes in DLD-1-miR-21 cells. A Kyoto Encyclopedia of Genes and Genomes (KEGG) pathway enrichment analysis was performed as described in "Materials and Methods". Differentially expressed genes (DEGs) in DLD-1-miR-21 cells were mapped to the KEGG proteasome pathway (hsa03050). The genes highlighted in red and green indicated the upregulated and downregulated genes in DLD-1-miR-21 cells. The original data are shown in Table S2.

To investigate whether the downregulation of genes related to the proteasome system reflected the prognostic impact of miR-21 overexpression in CRC, Kaplan-Meier survival plots were generated using the PROGgeneV2 prognostic database [14]. Two CRC patient datasets (GSE28722 and GSE28814) [15] with values of overall and metastasis-free survival were selected. Upregulated genes (PSME3, PSMA1, PSMA2, PSMA3, PSMB2, PSMB3, PSMB4, PSMB5, PSMB8, PSMB10, PSMC2, PSMC3, PSMC4, PSMC5, PSMC6, PSMD3, PSMD4, PSMD11, PSME1, PSMF1, and PSMD6) of the proteasome system (Table S2) were used as a combined gene signature for the miR-21-mediated downregulation of the proteasome 
pathway. Similar to the prognostic implication of miR-21 (Figure 1), only metastasis-free survival was predicted by the gene signature in CRC patients (Figure 6). CRC patients with a lower expression of the gene signature had poor metastasis-free survival (Figure 6B), which was opposite to the prognostic impact of miR-21 (Figure 1B).

A

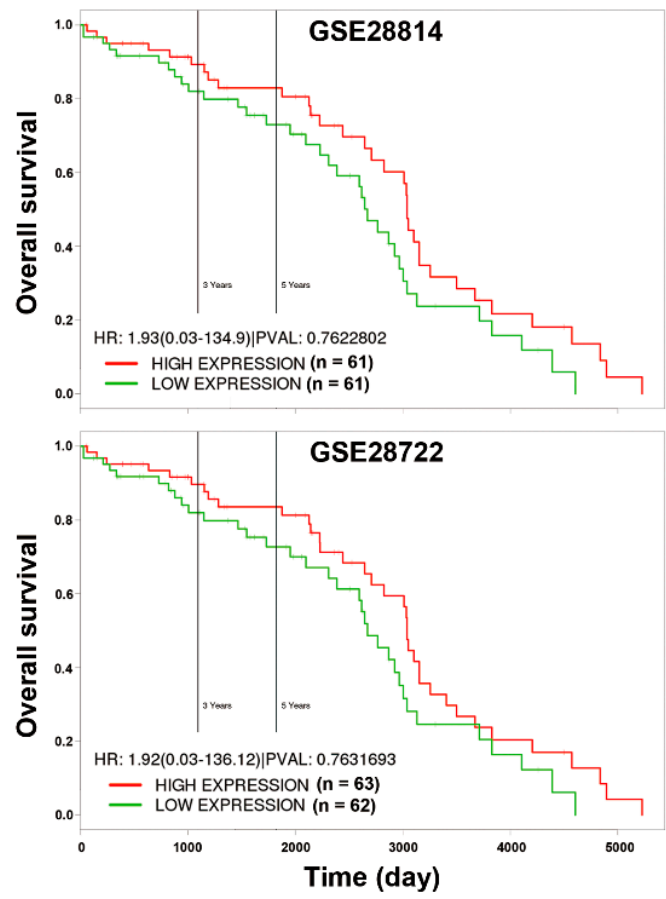

B

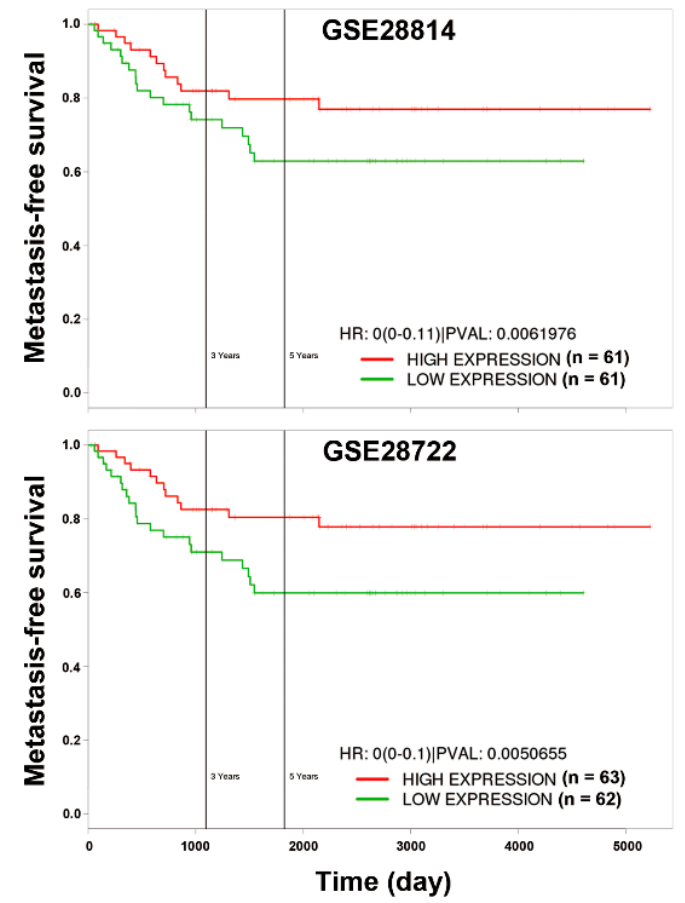

Figure 6. Prognostic impacts of proteasome gene alterations on overall (A) and metastasis-free (B) survival in colorectal cancer (CRC). The prognostic impact of the miR-21-downregulated proteasome gene signature (PSME3, PSMA1, PSMA2, PSMA3, PSMB2, PSMB3, PSMB4, PSMB5, PSMB8, PSMB10, PSMC2, PSMC3, PSMC4, PSMC5, PSMC6, PSMD3, PSMD4, PSMD11, PSME1, PSMF1, and PSMD6) in CRC was evaluated using the PROGgeneV2 database (http://www.compbio.iupui.edu/proggene/). Two CRC patient datasets (GSE28722 and GSE28814) were employed to generate the Kaplan-Meier survival plots. Patients with high $(n=61$ or 63$)$ and low $(n=61$ or 62$)$ miR-21 expression in GSE28722 and GSE28144, respectively, were bifurcated at the median value. HR, hazard ratio; PVAL, $p$ value.

\section{Discussion}

Approximately 25-50\% of CRC patients develop metastatic disease, in which liver metastasis (about 20\%) is the most common distant metastatic site [34,35]. Once metastasis has occurred, it is unlikely that the disease can be completely cured due to the development of drug resistance [17]. miR-21 is the most abundant miRNA in CRC, and is associated with tumor proliferation, invasion, and metastasis [36-38]. In this study, we found that CRC patients expressing high levels of miR-21-high had poor metastasis-free survival. In addition, miR-21 overexpression in CRC cells resulted in the development of topoisomerase inhibitor resistance. Therefore, a better characterization of the underlying molecular mechanisms of drug resistance induced by miR-21 overexpression will provide clinical benefits to control or prevent metastatic disease.

As an oncogenic miRNA, miR-21 is well-known to mediate resistance to radiation and chemotherapy in various cancer types [39-41]. However, its role in CRC drug resistance is less clear. 5-FU-based chemotherapy in combination with oxaliplatin (such as FOLFOX) or irinotecan (such as FOLFIRI) is the standard regimen for CRC [2]. The upregulation of miR-21 has been found in drug-resistant CRC cell lines, including the FOLFOX (5-FU/leucovorin/oxaliplatin)-resistant HCT-116 and HT-29 cells [42], 5-FU-resistant DLD-1 and KM12C cells [43], oxaliplatin-resistant 
HCT-15 and SW480 cells [44], and doxorubicin-resistant HT-29 and LoVo cells [45]. miR-21-mediated FOLFOX resistance is associated with the upregulation of cancer stemness by inhibiting transforming growth factor beta receptor 2 (TGF $\beta R 2$ ) and activating the $\mathrm{Wnt} / \beta$-catenin pathway [42]. How miR-21 mediates the resistance of other drugs, such as oxaliplatin and doxorubicin, has not been characterized. In our study, we found that stable miR-21 overexpression led to the resistance to topoisomerase inhibitors (SN-38, VP-16, and doxorubicin) in DLD-1 cells. Mechanistically, miR-21 overexpression reduced VP-16-induced apoptosis and enhanced VP-16-induced autophagic flux. Whether SN-38 and doxorubicin acted in similar ways warrants further investigation. In contrast, miR-21 overexpression did not influence the sensitivity of DLD-1 cells to 5-FU. It has been found that mismatch repair (MMR)-proficient CRC cells respond better to 5-FU therapy [46,47]. In addition, miR-21 overexpression induces 5-FU resistance by downregulating the core MMR recognition protein complex, human mutS homolog 2 (hMSH2) and 6 (hMSH6) in CRC [48]. DLD-1 cells were defective in the hMSH6 gene [49], which may partly explain the inconsistent role of miR-21 in 5-FU resistance.

Recently, the role of autophagy in topoisomerase inhibitor resistance has received attention in this field [50]. Since autophagy plays dual functions in cancer, the modulation of autophagy, either by reversing cytoprotective autophagy or by promoting cytotoxic autophagy, could overcome cancer resistance to topoisomerase inhibitors [50-52]. Our results indicate that miR-21 overexpression stimulated autophagic flux, which antagonized topoisomerase inhibitor-induced apoptosis. The inhibition of autophagic flux by bafilomycin A1 or ATG7 knockdown thereby selectively killed DLD-1-miR-21 cells or potentiated VP-16-induced apoptosis, respectively. In contrast, the enhancement of autophagic flux by rapamycin exacerbated miR-21-mediated drug resistance.

The role of miR-21 in regulating autophagy is still controversial. miR-21 inhibits autophagy through inhibiting its target, PTEN, and the subsequent activation of AKT $[53,54]$. However, the activation of ERK by miR-21 promotes arsenite-induced autophagy [55]. In addition, miR-21 enhances autophagic flux through promoting lysosomal function [56]. Our results found that miR-21 may disrupt proteasome function through downregulating the related gene expression. As the compensative behavior between the proteasome and autophagy [30], miR-21-mediated impairment of the proteasome may lead to the overactivation of autophagy.

Our results implied that the clinical efficacy of chemotherapy containing topoisomerase inhibitors for CRC patients would be obstructed by miR-21 overexpression. However, it is argued that the dosages of anticancer drugs used for in vitro experiments are usually higher than those that can be achieved in clinical settings, and the effects observed in vitro may result from the clinically irrelevant off-target activities. It has been suggested that the maximum plasma concentration ( $\mathrm{Cmax}$ ) of a drug in clinic could be a parameter being reverse-translated to in vitro experimental designs [57]. The reported $\mathrm{Cmax}$ values for SN-38, doxorubicin, and VP-16 are $0.143 \mu \mathrm{M}, 6.73 \mu \mathrm{M}$, and $33.4 \mu \mathrm{M}$, respectively [57-60]. Therefore, the dosages of these drugs used in this study are clinically relevant.

\section{Conclusions}

In conclusion, we found that miR-21 overexpression induced the drug resistance of CRC cells to topoisomerase inhibitors through inhibiting apoptosis and enhancing autophagic flux. Bioinformatics analyses further provided in silico mechanistic insights into miR-21-mediated drug resistance. First, miR-21 overexpression mimics the gene signature of topoisomerase inhibitors, which may lead to the reduced responsiveness of CRC cells to drug treatment. Second, miR-21 overexpression inhibits the proteasome pathway through downregulating gene expression, which may lead to the enhancement of autophagic flux. Since the relationship between miR-21 and the proteasome pathway has never been investigated, further exploration is needed. 
Supplementary Materials: The following are available online at http://www.mdpi.com/2218-273X/9/9/467/s1, Figure S1: The correlation between drug activity and gene expression, Figure S2: The effect of VP-16 on miR-21 expression, Figure S3: Uncropped images of the blots, Table S1: Gene list for the Connectivity Map (CMap) analysis, Table S2: Gene list for KEGG proteasome pathway mapping, File S1: Differentially expressed genes in DLD-1-miR-21 vs. DLD-1-vector cells.

Author Contributions: J.-C.C. participated in the design of the study and drafted the manuscript. Y.-Y.H. participated in the design of the study and performed the bioinformatics analyses. H.-L.L., A.L., and C.-J.C. carried out the in vitro experiments. P.-M.Y. conceived and designed experiments, as well as coordinated and drafted the manuscript. All authors gave final approval for publication.

Funding: This research was funded by the health and welfare surcharge of tobacco products (WanFang Hospital, Chi-Mei Medical Center, and Hualien Tzu-Chi Hospital Joing Cancer Center Grant-Focus on Colon Cancer Research), grant number MOHW108-TDU-B-212-124020; the Ministry of Science and Technology, grant numbers MOST103-2320-B-038-052, MOST104-2320-B-038-005, MOST105-2320-B-038-002, MOST108-2314-B-038-010; the Ministry of Education, grant number DP2-108-21121-01-C-03-05; the Taipei Medical University, grant numbers TMU103-AE2-I04-4, TMU104-AE2-I02-4, TMU105-AE2-I03-4, TMU105-U-32, TMU106-F-005; and the Taipei Medical University - Shuang Ho Hospital, grant number 108TMU-SHH-19.

Acknowledgments: This work was financially supported by the "TMU Research Center of Cancer Translational Medicine" from The Featured Areas Research Center Program within the framework of the Higher Education Sprout Project by the Ministry of Education (MOE) in Taiwan. The authors thank the support of the Office of Research and Development (Taipei Medical University, Taipei, Taiwan) for English editing.

Conflicts of Interest: The authors declare no conflict of interest.

\section{References}

1. Siegel, R.L.; Miller, K.D.; Jemal, A. Cancer statistics, 2018. CA Cancer J. Clin. 2018, 68, 7-30. [CrossRef] [PubMed]

2. Waldner, M.J.; Neurath, M.F. The molecular therapy of colorectal cancer. Mol. Asp. Med. 2010, 31, $171-178$. [CrossRef] [PubMed]

3. Kasinski, A.L.; Slack, F.J. Epigenetics and genetics. MicroRNAs en route to the clinic: Progress in validating and targeting microRNAs for cancer therapy. Nat. Rev. Cancer 2011, 11, 849-864. [CrossRef] [PubMed]

4. Pekow, J.R.; Kwon, J.H. MicroRNAs in inflammatory bowel disease. Inflamm. Bowel Dis. 2012, 18, $187-193$. [CrossRef] [PubMed]

5. Volinia, S.; Calin, G.A.; Liu, C.G.; Ambs, S.; Cimmino, A.; Petrocca, F.; Visone, R.; Iorio, M.; Roldo, C.; Ferracin, M.; et al. A microRNA expression signature of human solid tumors defines cancer gene targets. Proc. Natl. Acad. Sci. USA 2006, 103, 2257-2261. [CrossRef] [PubMed]

6. Selcuklu, S.D.; Donoghue, M.T.; Spillane, C. miR-21 as a key regulator of oncogenic processes. Biochem. Soc. Trans. 2009, 37, 918-925. [CrossRef] [PubMed]

7. Krichevsky, A.M.; Gabriely, G. miR-21: A small multi-Faceted RNA. J. Cell. Mol. Med. 2009, 13, 39-53. [CrossRef] [PubMed]

8. Subramanian, A.; Narayan, R.; Corsello, S.M.; Peck, D.D.; Natoli, T.E.; Lu, X.; Gould, J.; Davis, J.F.; Tubelli, A.A.; Asiedu, J.K.; et al. A Next Generation Connectivity Map: L1000 Platform and the First 1,000,000 Profiles. Cell 2017, 171, 1437-1452. [CrossRef]

9. Rajapakse, V.N.; Luna, A.; Yamade, M.; Loman, L.; Varma, S.; Sunshine, M.; Iorio, F.; Sousa, F.G.; Elloumi, F.; Aladjem, M.I.; et al. CellMinerCDB for Integrative Cross-Database Genomics and Pharmacogenomics Analyses of Cancer Cell Lines. iScience 2018, 10, 247-264. [CrossRef]

10. Basu, A.; Bodycombe, N.E.; Cheah, J.H.; Price, E.V.; Liu, K.; Schaefer, G.I.; Ebright, R.Y.; Stewart, M.L.; Ito, D.; Wang, S.; et al. An interactive resource to identify cancer genetic and lineage dependencies targeted by small molecules. Cell 2013, 154, 1151-1161. [CrossRef]

11. Rees, M.G.; Seashore-Ludlow, B.; Cheah, J.H.; Adams, D.J.; Price, E.V.; Gill, S.; Javaid, S.; Coletti, M.E.; Jones, V.L.; Bodycombe, N.E.; et al. Correlating chemical sensitivity and basal gene expression reveals mechanism of action. Nat. Chem. Biol. 2016, 12, 109-116. [CrossRef] [PubMed]

12. Seashore-Ludlow, B.; Rees, M.G.; Cheah, J.H.; Cokol, M.; Price, E.V.; Coletti, M.E.; Jones, V.; Bodycombe, N.E.; Soule, C.K.; Gould, J.; et al. Harnessing Connectivity in a Large-Scale Small-Molecule Sensitivity Dataset. Cancer Discov. 2015, 5, 1210-1223. [CrossRef] [PubMed] 
13. Goswami, C.P.; Nakshatri, H. PROGmiR: A tool for identifying prognostic miRNA biomarkers in multiple cancers using publicly available data. J. Clin. Bioinform. 2012, 2, 23. [CrossRef] [PubMed]

14. Goswami, C.P.; Nakshatri, H. PROGgeneV2: Enhancements on the existing database. BMC Cancer 2014, 14, 970. [CrossRef] [PubMed]

15. Loboda, A.; Nebozhyn, M.V.; Watters, J.W.; Buser, C.A.; Shaw, P.M.; Huang, P.S.; Van't Veer, L.; Tollenaar, R.A.; Jackson, D.B.; Agrawal, D.; et al. EMT is the dominant program in human colon cancer. BMC Med. Genom. 2011, 4, 9. [CrossRef] [PubMed]

16. Asangani, I.A.; Rasheed, S.A.; Nikolova, D.A.; Leupold, J.H.; Colburn, N.H.; Post, S.; Allgayer, H. MicroRNA-21 (miR-21) post-Transcriptionally downregulates tumor suppressor Pdcd4 and stimulates invasion, intravasation and metastasis in colorectal cancer. Oncogene 2008, 27, 2128-2136. [CrossRef] [PubMed]

17. Shimada, H.; Tanaka, K.; Endou, I.; Ichikawa, Y. Treatment for colorectal liver metastases: A review. Langenbecks Arch. Surg. 2009, 394, 973-983. [CrossRef]

18. Barretina, J.; Caponigro, G.; Stransky, N.; Venkatesan, K.; Margolin, A.A.; Kim, S.; Wilson, C.J.; Lehar, J.; Kryukov, G.V.; Sonkin, D.; et al. The Cancer Cell Line Encyclopedia enables predictive modelling of anticancer drug sensitivity. Nature 2012, 483, 603-607. [CrossRef]

19. Cancer Cell Line Encyclopedia Consortium; Genomics of Drug Sensitivity in Cancer Consortium. Pharmacogenomic agreement between two cancer cell line data sets. Nature 2015, 528, 84-87. [CrossRef]

20. Krishnakumar, R.; Kraus, W.L. The PARP side of the nucleus: Molecular actions, physiological outcomes, and clinical targets. Mol. Cell 2010, 39, 8-24. [CrossRef]

21. Sugimoto, Y.; Tsukahara, S.; Oh-hara, T.; Isoe, T.; Tsuruo, T. Decreased expression of DNA topoisomerase I in camptothecin-Resistant tumor cell lines as determined by a monoclonal antibody. Cancer Res. 1990, 50, 6925-6930. [PubMed]

22. Sugimoto, Y.; Tsukahara, S.; Oh-hara, T.; Liu, L.F.; Tsuruo, T. Elevated expression of DNA topoisomerase II in camptothecin-Resistant human tumor cell lines. Cancer Res. 1990, 50, 7962-7965. [PubMed]

23. Hsiang, Y.H.; Liu, L.F. Identification of mammalian DNA topoisomerase I as an intracellular target of the anticancer drug camptothecin. Cancer Res. 1988, 48, 1722-1726. [PubMed]

24. Kroemer, G.; Galluzzi, L.; Vandenabeele, P.; Abrams, J.; Alnemri, E.S.; Baehrecke, E.H.; Blagosklonny, M.V.; El-Deiry, W.S.; Golstein, P.; Green, D.R.; et al. Classification of cell death: Recommendations of the Nomenclature Committee on Cell Death 2009. Cell Death Differ. 2009, 16, 3-11. [CrossRef] [PubMed]

25. Maiuri, M.C.; Zalckvar, E.; Kimchi, A.; Kroemer, G. Self-Eating and self-Killing: Crosstalk between autophagy and apoptosis. Nat. Rev. Mol. Cell Biol. 2007, 8, 741-752. [CrossRef] [PubMed]

26. Klionsky, D.J.; Abdalla, F.C.; Abeliovich, H.; Abraham, R.T.; Acevedo-Arozena, A.; Adeli, K.; Agholme, L.; Agnello, M.; Agostinis, P.; Aguirre-Ghiso, J.A.; et al. Guidelines for the use and interpretation of assays for monitoring autophagy. Autophagy 2012, 8, 445-544. [CrossRef]

27. Lamb, J. The Connectivity Map: A new tool for biomedical research. Nat. Rev. Cancer 2007, 7, 54-60. [CrossRef]

28. Lamb, J.; Crawford, E.D.; Peck, D.; Modell, J.W.; Blat, I.C.; Wrobel, M.J.; Lerner, J.; Brunet, J.P.; Subramanian, A.; Ross, K.N.; et al. The Connectivity Map: Using gene-Expression signatures to connect small molecules, genes, and disease. Science 2006, 313, 1929-1935. [CrossRef]

29. Delgado, M.E.; Dyck, L.; Laussmann, M.A.; Rehm, M. Modulation of apoptosis sensitivity through the interplay with autophagic and proteasomal degradation pathways. Cell Death Dis. 2014, 5, 1011. [CrossRef]

30. Ding, W.X.; Ni, H.M.; Gao, W.; Yoshimori, T.; Stolz, D.B.; Ron, D.; Yin, X.M. Linking of autophagy to ubiquitin-proteasome system is important for the regulation of endoplasmic reticulum stress and cell viability. Am. J. Pathol. 2007, 171, 513-524. [CrossRef]

31. Kanehisa, M.; Furumichi, M.; Tanabe, M.; Sato, Y.; Morishima, K. KEGG: New perspectives on genomes, pathways, diseases and drugs. Nucleic Acids Res. 2017, 45, D353-D361. [CrossRef] [PubMed]

32. Kanehisa, M.; Goto, S. KEGG: Kyoto encyclopedia of genes and genomes. Nucleic Acids Res. 2000, 28, 27-30. [CrossRef] [PubMed]

33. Kanehisa, M.; Sato, Y.; Furumichi, M.; Morishima, K.; Tanabe, M. New approach for understanding genome variations in KEGG. Nucleic Acids Res. 2019, 47, 590-595. [CrossRef] [PubMed]

34. Kouzminova, N.; Lu, T.; Lin, A.Y. Molecular basis of colorectal cancer. New Engl. J. Med. 2010, 362, 1245-1246. [CrossRef] [PubMed] 
35. Reissfelder, C.; Rahbari, N.N.; Koch, M.; Ulrich, A.; Pfeilschifter, I.; Waltert, A.; Muller, S.A.; Schemmer, P.; Buchler, M.W.; Weitz, J. Validation of prognostic scoring systems for patients undergoing resection of colorectal cancer liver metastases. Ann. Surg. Oncol. 2009, 16, 3279-3288. [CrossRef]

36. Schee, K.; Lorenz, S.; Worren, M.M.; Gunther, C.C.; Holden, M.; Hovig, E.; Fodstad, O.; Meza-Zepeda, L.A.; Flatmark, K. Deep Sequencing the MicroRNA Transcriptome in Colorectal Cancer. PLoS ONE 2013, 8, 66165. [CrossRef]

37. Sun, G.; Cheng, Y.W.; Lai, L.; Huang, T.C.; Wang, J.; Wu, X.; Wang, Y.; Huang, Y.; Wang, J.; Zhang, K.; et al. Signature miRNAs in colorectal cancers were revealed using a bias reduction small RNA deep sequencing protocol. Oncotarget 2016, 7, 3857-3872. [CrossRef]

38. Zhao, J.; Zhang, Y.; Zhao, G. Emerging role of microRNA-21 in colorectal cancer. Cancer Biomark. 2015, 15, 219-226. [CrossRef]

39. Hong, L.; Han, Y.; Zhang, Y.; Zhang, H.; Zhao, Q.; Wu, K.; Fan, D. MicroRNA-21: A therapeutic target for reversing drug resistance in cancer. Expert Opin. Ther. Targets 2013, 17, 1073-1080. [CrossRef]

40. Javanmardi, S.; Aghamaali, M.R.; Abolmaali, S.S.; Mohammadi, S.; Tamaddon, A.M. miR-21, An Oncogenic Target miRNA for Cancer Therapy: Molecular Mechanisms and Recent Advancements in Chemo and Radio-resistance. Curr. Gene Ther. 2017, 16, 375-389. [CrossRef]

41. Pan, X.; Wang, Z.X.; Wang, R. MicroRNA-21: A novel therapeutic target in human cancer. Cancer Biol. Ther. 2010, 10, 1224-1232. [CrossRef] [PubMed]

42. Yu, Y.; Kanwar, S.S.; Patel, B.B.; Oh, P.S.; Nautiyal, J.; Sarkar, F.H.; Majumdar, A.P. MicroRNA-21 induces stemness by downregulating transforming growth factor beta receptor 2 (TGFbetaR2) in colon cancer cells. Carcinogenesis 2012, 33, 68-76. [CrossRef] [PubMed]

43. Kurokawa, K.; Tanahashi, T.; Iima, T.; Yamamoto, Y.; Akaike, Y.; Nishida, K.; Masuda, K.; Kuwano, Y.; Murakami, Y.; Fukushima, M.; et al. Role of miR-19b and its target mRNAs in 5-Fluorouracil resistance in colon cancer cells. J. Gastroenterol. 2012, 47, 883-895. [CrossRef] [PubMed]

44. Guo, Y.; Pang, Y.; Gao, X.; Zhao, M.; Zhang, X.; Zhang, H.; Xuan, B.; Wang, Y. MicroRNA-137 chemosensitizes colon cancer cells to the chemotherapeutic drug oxaliplatin (OXA) by targeting YBX1. Cancer Biomark. 2017, 18, 1-9. [CrossRef] [PubMed]

45. Qu, J.; Zhao, L.; Zhang, P.; Wang, J.; Xu, N.; Mi, W.; Jiang, X.; Zhang, C.; Qu, J. MicroRNA-195 chemosensitizes colon cancer cells to the chemotherapeutic drug doxorubicin by targeting the first binding site of BCL2L2 mRNA. J. Cell. Physiol. 2015, 230, 535-545. [CrossRef] [PubMed]

46. Hewish, M.; Lord, C.J.; Martin, S.A.; Cunningham, D.; Ashworth, A. Mismatch repair deficient colorectal cancer in the era of personalized treatment. Nat. Rev. Clin. Oncol. 2010, 7, 197-208. [CrossRef] [PubMed]

47. Meyers, M.; Wagner, M.W.; Mazurek, A.; Schmutte, C.; Fishel, R.; Boothman, D.A. DNA mismatch repair-Dependent response to fluoropyrimidine-Generated damage. J. Biol. Chem. 2005, 280, 5516-5526. [CrossRef]

48. Valeri, N.; Gasparini, P.; Braconi, C.; Paone, A.; Lovat, F.; Fabbri, M.; Sumani, K.M.; Alder, H.; Amadori, D.; Patel, T.; et al. MicroRNA-21 induces resistance to 5-Fluorouracil by down-Regulating human DNA MutS homolog 2 (hMSH2). Proc. Natl. Acad. Sci. USA 2010, 107, 21098-21103. [CrossRef]

49. Papadopoulos, N.; Nicolaides, N.C.; Liu, B.; Parsons, R.; Lengauer, C.; Palombo, F.; D'Arrigo, A.; Markowitz, S.; Willson, J.K.; Kinzler, K.W.; et al. Mutations of GTBP in genetically unstable cells. Science 1995, 268, 1915-1917. [CrossRef]

50. Chen, C.; Lu, L.; Yan, S.; Yi, H.; Yao, H.; Wu, D.; He, G.; Tao, X.; Deng, X. Autophagy and doxorubicin resistance in cancer. Anti-Cancer Drugs 2018, 29, 1-9. [CrossRef]

51. Biasoli, D.; Kahn, S.A.; Cornelio, T.A.; Furtado, M.; Campanati, L.; Chneiweiss, H.; Moura-Neto, V.; Borges, H.L. Retinoblastoma protein regulates the crosstalk between autophagy and apoptosis, and favors glioblastoma resistance to etoposide. Cell Death Dis. 2013, 4, 767. [CrossRef] [PubMed]

52. Chen, M.C.; Lee, N.H.; Ho, T.J.; Hsu, H.H.; Kuo, C.H.; Kuo, W.W.; Lin, Y.M.; Tsai, F.J.; Tsai, C.H.; Huang, C.Y. Resistance to irinotecan (CPT-11) activates epidermal growth factor receptor/nuclear factor kappa B and increases cellular metastasis and autophagy in LoVo colon cancer cells. Cancer Lett. 2014, 349, 51-60. [CrossRef] [PubMed]

53. He, C.; Dong, X.; Zhai, B.; Jiang, X.; Dong, D.; Li, B.; Jiang, H.; Xu, S.; Sun, X. MiR-21 mediates sorafenib resistance of hepatocellular carcinoma cells by inhibiting autophagy via the PTEN/Akt pathway. Oncotarget 2015, 6, 28867-28881. [CrossRef] 
54. Song, L.; Liu, S.; Zhang, L.; Yao, H.; Gao, F.; Xu, D.; Li, Q. MiR-21 modulates radiosensitivity of cervical cancer through inhibiting autophagy via the PTEN/Akt/HIF-1alpha feedback loop and the Akt-mTOR signaling pathway. Tumour Biol. 2016, 37, 12161-12168. [CrossRef]

55. Liu, X.; Luo, F.; Ling, M.; Lu, L.; Shi, L.; Lu, X.; Xu, H.; Chen, C.; Yang, Q.; Xue, J.; et al. MicroRNA-21 activation of ERK signaling via PTEN is involved in arsenite-Induced autophagy in human hepatic L-02 cells. Toxicol. Lett. 2016, 252, 1-10. [CrossRef] [PubMed]

56. Tang, F.; Yang, T.L.; Zhang, Z.; Li, X.G.; Zhong, Q.Q.; Zhao, T.T.; Gong, L. MicroRNA-21 suppresses ox-LDL-Induced human aortic endothelial cells injuries in atherosclerosis through enhancement of autophagic flux: Involvement in promotion of lysosomal function. Exp. Cell Res. 2017, 359, 374-383. [CrossRef]

57. Liston, D.R.; Davis, M. Clinically Relevant Concentrations of Anticancer Drugs: A Guide for Nonclinical Studies. Clin. Cancer Res. 2017, 23, 3489-3498. [CrossRef] [PubMed]

58. Rothenberg, M.L.; Eckardt, J.R.; Kuhn, J.G.; Burris, H.A., 3rd; Nelson, J.; Hilsenbeck, S.G.; Rodriguez, G.I.; Thurman, A.M.; Smith, L.S.; Eckhardt, S.G.; et al. Phase II trial of irinotecan in patients with progressive or rapidly recurrent colorectal cancer. J. Clin. Oncol. 1996, 14, 1128-1135. [CrossRef]

59. Sparreboom, A.; Planting, A.S.; Jewell, R.C.; van der Burg, M.E.; van der Gaast, A.; de Bruijn, P.; Loos, W.J.; Nooter, K.; Chandler, L.H.; Paul, E.M.; et al. Clinical pharmacokinetics of doxorubicin in combination with GF120918, a potent inhibitor of MDR1 P-Glycoprotein. Anti-Cancer Drugs 1999, 10, 719-728. [CrossRef]

60. Van Zuylen, L.; Schellens, J.H.; Goey, S.H.; Pronk, L.C.; de Boer-Dennert, M.M.; Loos, W.J.; Ma, J.; Stoter, G.; Verweij, J. Phase I and pharmacologic study of the arotinoid Ro 40-8757 in combination with cisplatin and etoposide in patients with non-Small cell lung cancer. Anti-Cancer Drugs 1999, 10, 361-368. [CrossRef] [PubMed]

(C) 2019 by the authors. Licensee MDPI, Basel, Switzerland. This article is an open access article distributed under the terms and conditions of the Creative Commons Attribution (CC BY) license (http://creativecommons.org/licenses/by/4.0/). 